\title{
TUNABLE UNIVERSAL FILTER WITH CURRENT FOLLOWER AND TRANSCONDUCTANCE AMPLIFIERS AND STUDY OF PARASITIC INFLUENCES
}

\author{
Jan JEŘÁBEK * - Roman ŠOTNER ${ }^{* *}-$ Kamil VRBA*
}

\begin{abstract}
A universal filter with dual-output current follower (DO-CF), two transconductance amplifiers (OTAs) and two passive elements is presented in this paper. The filter is tunable, of the single-input multiple-output (SIMO) type, and operates in the current mode. Our solution utilizes a low-impedance input node and high-impedance outputs. All types of the active elements used can be realized using our UCC-N1B 0520 integrated circuit and therefore the paper contains not only simulation results that were obtained with the help of behavioral model of the UCC-N1B 0520 element, but also the characteristics that were gained by measurement with the mentioned circuit. The presented simulation and measurement results prove the quality of designed filter. Similar multi-loop structures are very-well known, but there are some drawbacks that are not discussed in similar papers. This paper also contains detailed study of parasitic influences on the filter performance.
\end{abstract}

K e y w o r d s: BOTA, DO-CF, current mode, SIMO filter, tunable filter, universal filter

\section{INTRODUCTION}

The development of analog frequency filters in the current mode [1] with various types of active elements still attracts many researchers' attention. Many different types of active elements are used in filtering circuitries, starting from the simple current followers (CF) [2,3], through dual- or multiple-output current followers (DO-CF, MOCF) $[4,5]$, OTA amplifiers, mostly in the form of the OTA-C filter $[6,7]$, current conveyors (CC) of different generations $[8,9]$ up to more complex active elements such as the Current Differencing Transconductance Amplifier (CDTA) [10-12], which consists of a differential current follower and a transconductance amplifier, and also the Current Follower Transconductance Amplifier (CFTA) $[13,14]$, which contains a simple current follower and also a transconductance amplifier.

Two basic techniques can be recognized in cited papers. The first method is based on the design of more complex filtering structures with simple active elements, for example in $[2,15,16,21]$. The second approach is contrary which means that the final filtering structures are simpler, but the active elements are more complex, typically in $[11,20,22]$. It should be noted that the schematic of filtering structures in second case seems simpler than in the first case only because a smaller number of active elements are present in the circuitry. The application of more complex active elements in filtering structures limits the variability of solutions when designing specific structures and it could significantly complicate the design and raise the final price. The combination of current followers and transconductance amplifiers is really advantageous for the design of filtering structures in the current mode, as shown in [10-14]; this paper is therefore also focused on the utilization of the above elements. Some recent works are compared in Tab. 1.

Table 1 could be summarized into the several conclusions. Some recently proposed conceptions contain too many passive elements $[2,15,16,21,22,26]$, or maybe unreasonably many active elements $[20,26]$ but in several cases, it is necessary for the independent $\omega_{C}$ and $\mathrm{Q}$ control. However there are simpler solutions, for example $[19,27]$ with $\omega_{C}$ and $Q$ control included. Electronic adjusting and tuning is one of the today's most important features for common applications in the signal processing. Unfortunately some of mentioned solutions do not have this feature (for example $[15,16]$ ) or it was not verified even if it is theoretically possible (for example $[18,21,28])$.

Our approach is to deal with partial elements, DO$\mathrm{CF}$ and BOTA in particular. It gives us the possibility of greater variability and we can reach a universal solution more easily. The benefits of the solution presented are: simplicity (only two passive elements - grounded capacitors), universality, tunability and relative sensitivities to all parameters of the filter are low. The circuitry designed is of the Single Input Multiple Output (SIMO) type. Both passive elements are grounded. All the features mentioned form good prerequisites for the application of this structure. Some features of active elements that could cause drawbacks or specific problems in frequency responses are discussed.

\section{USED ACTIVE ELEMENTS}

The designed filter includes two types of active elements. The first of them is the Dual-Output Current Fol-

\footnotetext{
* Department of Telecommunications, Faculty of Electrical Engineering and Communication, jerabekj@feec.vutbr.cz, ${ }^{* *}$ Department of Radio Electronics, Faculty of Electrical Engineering and Communication, xsotne00@stud.feec.vutbr.cz; University of Technology, Purkynova 118, 61200 Brno, Czech Republic
} 
Table 1. Comparison of several most-recent solutions (both voltage and current mode)

\begin{tabular}{|c|c|c|c|c|c|c|c|c|}
\hline Previous work & $\begin{array}{l}\text { Number } \\
\text { of active } \\
\text { elements }\end{array}$ & $\begin{array}{l}\text { Fabrication } \\
\text { technology }\end{array}$ & $\begin{array}{l}\text { Number } \\
\text { of passive } \\
\text { elements }\end{array}$ & $\begin{array}{c}\omega_{C} \\
\text { control }\end{array}$ & $\begin{array}{c}Q \\
\text { control }\end{array}$ & $\begin{array}{c}f_{0} \\
\text { tuning } \\
\text { range }(\mathrm{Hz})\end{array}$ & $\begin{array}{c}\text { simulated/ } \\
\text { measured }\end{array}$ & $\begin{array}{c}\text { Controlled } \\
\text { via }\end{array}$ \\
\hline Senani [2] & 4 & CMOS & 5 & no & no & - & yes/no & - \\
\hline Tangsrirat [5] & 2 & BIPOLAR & 2 & no & no & - & yes/no & - \\
\hline Tangsrirat [8] & 4 & BIPOLAR & 2 & yes & yes & $12 \mathrm{k}-800 \mathrm{k}$ & yes/no & $\begin{array}{l}R_{x} \text { (bias } \\
\text { currents) }\end{array}$ \\
\hline Minaei [15] & 2 & CMOS & 6 & no & no & - & yes/no & - \\
\hline Horng [16] & 3 & CMOS & 6 & no & no & - & yes/no & - \\
\hline Horng [18] & 3 & CMOS & 4 & not tested & not tested & - & yes/no & - \\
\hline Wang [19] & $3-4$ & BIPOLAR & 2 & yes & yes & $100 \mathrm{k}-8 \mathrm{M}$ & yes/no & $\begin{array}{l}R_{x} \text { (bias } \\
\text { currents) }\end{array}$ \\
\hline $\begin{array}{r}\text { Siripruchyanum } \\
{[20]}\end{array}$ & 5 & BIPOLAR & 2 & yes & yes & $200 \mathrm{k}-800 \mathrm{k}$ & yes/no & $\begin{array}{l}R_{x}, g_{m} \text { (bias } \\
\text { currents) }\end{array}$ \\
\hline Horng [21] & 2 & CMOS & 5 & not tested & not tested & - & yes/no & - \\
\hline Minaei [22] & 3 & CMOS & $4-5$ & not tested & yes & - & yes/no & - \\
\hline $\begin{array}{r}\text { Siripruchyanum } \\
{[25]}\end{array}$ & 1 & BIPOLAR & 2 & yes & no & - & yes/no & $\begin{array}{l}R_{p}, R_{n} \text { (bias } \\
\text { currents) }\end{array}$ \\
\hline Kamat [26] & $1-5$ & CMOS & $1-6$ & not tested & yes & - & yes/no & - \\
\hline Lee $[27],[28]$ & $4-5$ & CMOS & 2 & not tested & not tested & - & yes/no & - \\
\hline Proposed & & $\begin{array}{l}\text { CMOS and } \\
\text { commercial } \\
\text { ICs }\end{array}$ & 2 & yes & no & $255 \mathrm{k}-2.3 \mathrm{M}$ & yes/yes & $g_{m}$ \\
\hline
\end{tabular}
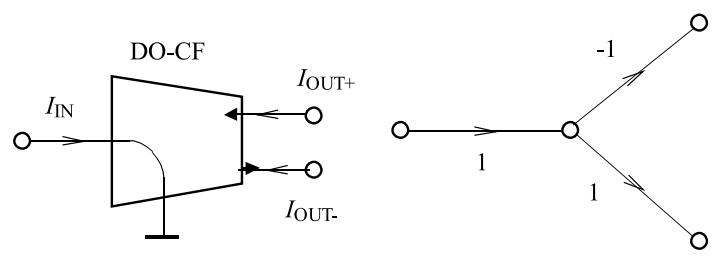

Fig. 1. Schematic of the Dual-Output Current Follower (DO-CF)

lower (DO-CF). Its schematic is shown in Fig. 1. DO$\mathrm{CF}$ can be formed discretely in several ways. The simplest method is to use the Universal Current Conveyor (UCC) [15], which can be simply connected as a dual- or multiple-output current follower. Two DO-CF elements can be implemented by one UCC-N1B 0520 integrated circuit because on chip contains $\mathrm{CCII}+/$ - together with UCC. The behavior of the DO-CF is described by the simple formulas

$$
\mathbf{I}_{\mathrm{OUT}+}=-\boldsymbol{I}_{\mathrm{OUT}-}=\boldsymbol{I}_{\mathrm{IN}}
$$

The second type of active element is the Balanced Operational Transconductance Amplifier (BOTA). The BOTA schematic is shown in Fig. 2a. Relations that describe the BOTA behavior are

$$
\boldsymbol{I}_{\mathrm{OUT}+}=-\boldsymbol{I}_{\mathrm{OUT}-}=g_{m} V_{I}=g_{m}\left(\boldsymbol{V}_{\mathrm{IN}+}-\boldsymbol{V}_{\mathrm{IN}-}\right) .
$$

MAX435 [16] is one of the circuits that are commercially available on the market and able to work as OTA. We can also compile the BOTA element from two single-output OTAs, for example the OPA861 circuits [17]. This circuit, however, does not provide the required parameters and in order to form a Multiple-Output OTA (MOTA), four OPA861 would be necessary. It is therefore better to make a BOTA or MOTA via the structure shown in Fig. 2b. It is obvious that one UCC and one resistor are sufficient enough to produce a BOTA or MOTA. The transconductance of such a connection of the UCC circuit is equal to $g_{m} \approx 1 / R$.

\section{DESIGNED FILTER}

The universal second-order filtering structure with a minimum number of passive components and included possibility to tune the characteristic frequency was the goal of the design. Possible circuits were analyzed by the SFG method and obtained solution is depicted in Fig. 3. The filter consists of one DO-CF element and two OTA elements (MOTA and BOTA). Two grounded capacitors are connected in nodes between active elements. The transfer functions of the designed circuit are given by

$$
\begin{aligned}
\frac{\boldsymbol{I}_{L P}}{\boldsymbol{I}_{I N}} & =\frac{g_{m 1} g_{m 2}}{D}, \\
\frac{\boldsymbol{I}_{i B P}}{\boldsymbol{I}_{I N}} & =-\frac{s C_{2} g_{m 1}}{D}, \\
\frac{\boldsymbol{I}_{B S}}{\boldsymbol{I}_{I N}} & =\frac{\boldsymbol{I}_{H P}+\boldsymbol{I}_{L P}}{\boldsymbol{I}_{I N}}=\frac{s^{2} C_{1} C_{2}+g_{m 1} g_{m 2}}{D},
\end{aligned}
$$



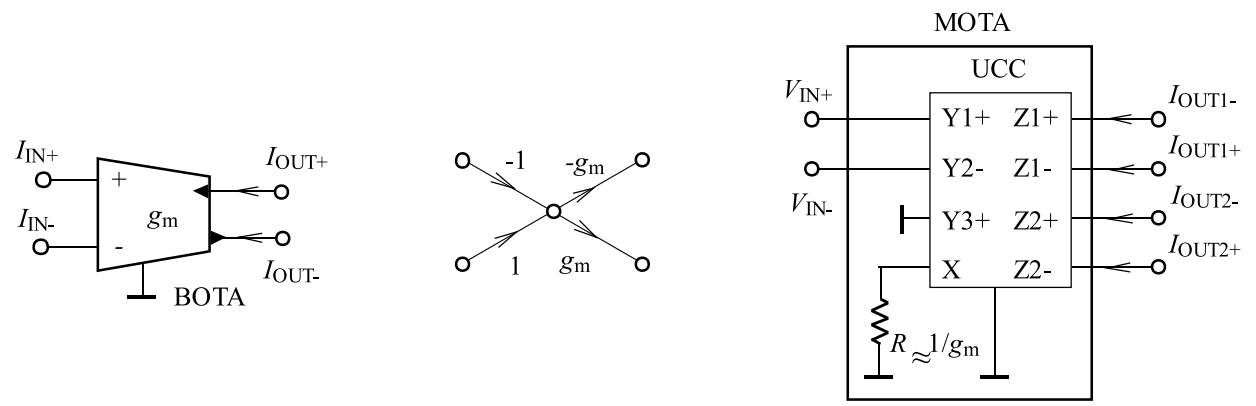

Fig. 2. a) Schematic of the Balanced Operational Transconductance Amplifier (BOTA), b) Circuitry forming MOTA with the help of one UCC

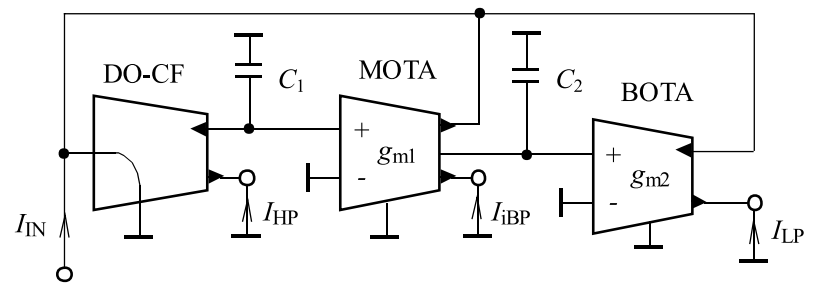

Fig. 3. Designed universal tunable filter formed by just three active elements and two passive elements

$$
\begin{aligned}
\frac{\boldsymbol{I}_{H P}}{\boldsymbol{I}_{I N}} & =\frac{s^{2} C_{1} C_{2}}{D} \\
\frac{\boldsymbol{I}_{A P}}{\boldsymbol{I}_{I N}} & =\frac{\boldsymbol{I}_{H P}+\boldsymbol{I}_{i B P}+\boldsymbol{I}_{L P}}{\boldsymbol{I}_{I N}} \\
& =\frac{s^{2} C_{1} C_{2}-s C_{2} g_{m 1}+g_{m 1} g_{m 2}}{D},
\end{aligned}
$$

where

$$
D=s^{2} C_{1} C_{2}+s C_{2} g_{m 1}+g_{m 1} g_{m 2}=0 .
$$

Equations (3)-(8) are valid without any condition or assumption of equality. The pass band gain is unity $(0 \mathrm{~dB})$ for each transfer function type. It is obvious that the designed circuit is universal because five standard types of transfer function are present. The pole frequency is controlled by a simultaneous change of $g_{m 1}$ and $g_{m 2}$.

\section{SENSITIVITY ANALYSIS}

If we consider all transfer coefficients that are present in the circuit, characteristic eq. (8) of the circuit from Fig. 3 will change to

$$
D=s^{2} C_{1} C_{2}+s C_{2} g_{m 1}+g_{m 1} g_{m 2} \beta_{1}=0,
$$

where $\beta_{1}$ represents the transfer of the DO-CF element, which affects both loops of the circuit. The angular frequency and the quality factor are for all transfer functions expressed by

$$
\begin{aligned}
\omega_{0} & =\sqrt{g_{m 1} g_{m 2} \beta_{1} / C_{1} C_{2}}, \\
Q & =\sqrt{g_{m 2} \beta_{1} C_{1} / g_{m 1} C_{2}} .
\end{aligned}
$$

The relative sensitivities of the angular frequency and of the quality factor to individual components are equal to

$$
\begin{gathered}
S_{\beta_{1}}^{\omega_{0}}=S_{g_{m 1}}^{\omega_{0}}=S_{g_{m 2}}^{\omega_{0}}=0.5, \\
S_{C_{1}}^{\omega_{0}}=S_{C_{2}}^{\omega_{0}}=S_{g m 1}^{Q}=-0.5 \\
S_{\beta_{1}}^{Q}=S_{g_{m 2}}^{Q}=S_{C_{1}}^{Q}=0.5 .
\end{gathered}
$$

From (12)-(14) it is obvious that all relative sensitivities are low.

\section{INFLUENCES OF ACTIVE ELEMENTS PARASITICS}

Non-ideal active elements are depicted in Fig. 4a and Fig. 4b. Parasitic analysis deals mainly with input and output properties of used active element that cause significant problems in the frequency domain. Note that in Fig. 4a and Fig. 4b only one output of active element is shown for clarity, but we suppose that all outputs have very similar features. Important parasitic admittances of the filter (signed as $Y_{s}$ and $Y_{p}$ ) caused by the real input and output properties of used active elements are shown in Fig. 4c. Common input and output parameters of $\mathrm{CF}$ are $R_{\text {inp_CF }} \sim 2 \Omega, C_{\text {inp_CF }} \sim 3 \mathrm{pF}, R_{\text {out_CF }} \sim 200 \mathrm{k} \Omega$, $C_{\text {out_CF }} \sim 0.6 \mathrm{pF}$. Common small signal parameters of MOTA are $R_{\text {inp_MOTA }} \sim 1 \mathrm{G} \Omega, C_{\text {inp_MOTA }} \sim 1 \mathrm{pF}$, $R_{\text {out_MOTA }} \sim 200 \mathrm{k} \Omega, C_{\text {out_MOTA }}=0.6 \mathrm{pF}$. BOTA $($ represented by MAX435, for instance) has commonly the following parameters $R_{\text {inp_BOTA }} \sim 200 \mathrm{k} \Omega, C_{\text {inp_BOTA }} \sim$ $3 \mathrm{pF}, R_{\text {out_BOтA }} \sim 3.5 \mathrm{k} \Omega, C_{\text {out_BOtA }} \sim 5 \mathrm{pF}$.

We suppose four locations (three nodes and one serial admittance leading to the current input of DO-CF) where parasitics cause the highest impact. These parasitic admittances (Fig. 4c) can be expressed as

$$
\begin{aligned}
Y_{p 1}=G_{p_{1}} & +s C_{p 1}=\frac{1}{R_{\text {out_CF }}}+\frac{1}{R_{\text {inp_MOTA }}} \\
& +s\left(C_{\text {out_CF }}+C_{\text {inp_MOTA }}\right)
\end{aligned}
$$

$$
\begin{aligned}
Y_{p 2}=G_{p_{2}} & +s C_{p 2}=\frac{1}{R_{\text {out_MOTA }}}+\frac{1}{R_{\text {inp_BOTA }}} \\
& +s\left(C_{\text {out_MOTA }}+C_{\text {inp_BOTA }}\right)
\end{aligned}
$$




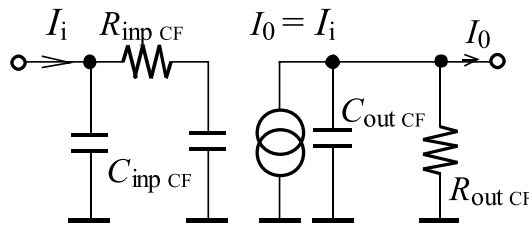

(a)

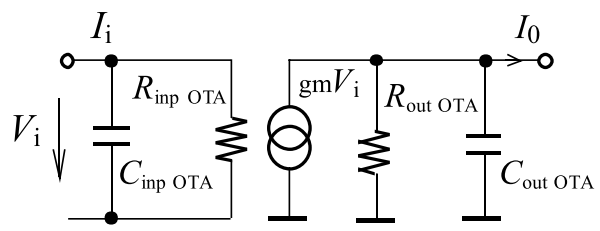

(b)

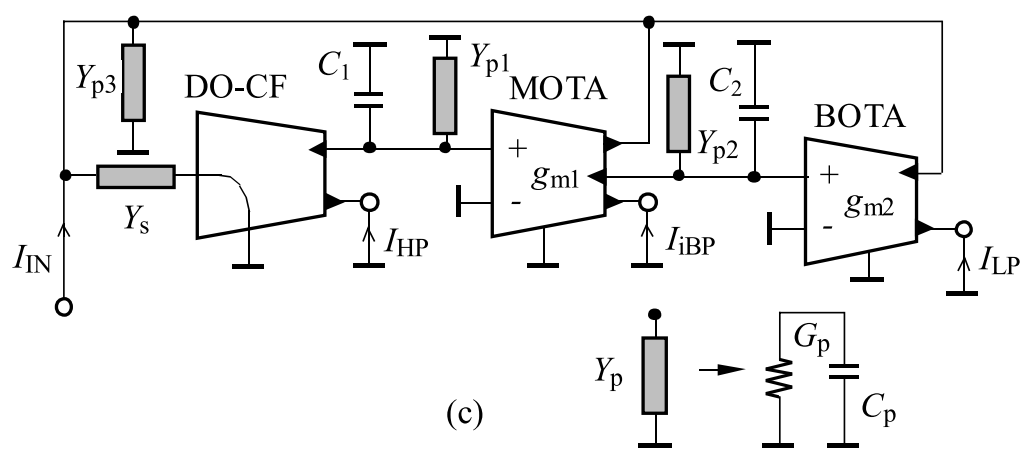

Fig. 4. a) Non-ideal model of current follower, b) non-ideal model of transconductance amplifier, c) important parasitic influences focused to specific places in circuit

$$
\begin{aligned}
Y_{p 3}=G_{p_{3}} & +s C_{p 3}=\frac{1}{R_{\text {out_MOTA }}}+\frac{1}{R_{\text {out_BOTA }}} \\
& +s\left(C_{\text {out_MOTA }}+C_{\text {out_BOTA }}\right) \\
Y_{s}= & G_{s}+s C_{s}=\frac{1}{R_{\text {inp_CF }}}+s C_{\text {inp_CF }} .
\end{aligned}
$$

Denominator of the transfer function changed to

$$
D^{\prime}(s)=b_{3} s^{3}+b_{2} s^{2}+b_{1} s+b_{0},
$$

where coefficients are as follows

$$
\begin{gathered}
b_{3}=C_{1} C_{2}\left(C_{p 3}+C_{s}\right)+C_{1}\left(C_{p 2} C_{p 3}+C_{p 2} C_{s}\right)+ \\
C_{2}\left(C_{p 1} C_{s}+C_{p 1} C_{p 3}\right)+C_{p 1} C_{p 2} C_{p 3}+C_{p 1} C_{p 2} C_{s},
\end{gathered}
$$

$$
\begin{gathered}
b_{2}=g_{m 1} C_{s}\left(C_{2}+C_{p 2}\right)-C_{1} C_{2}\left(G_{s}+G_{p 3}\right) \\
-\left(C_{p 1}+C_{1}\right)\left(G_{p 2} C_{p 3}+G_{p 3} C_{p 2}+G_{s} C_{p 2}+G_{p 2} C_{s}\right) \\
-G_{p 1} C_{p 3}\left(C_{2}+C_{p 2}\right)-C_{2}\left(G_{p 1} C_{s}+C_{p 1} G_{s}\right. \\
\left.\quad+C_{p 1} G_{p 3}\right)-G_{p 1} C_{p 2} C_{s}
\end{gathered}
$$

$$
\begin{aligned}
& b_{1}=C_{s}\left(g_{m 1} g_{m 2}+g_{m 1} G_{p 2}\right) \\
& -\left(C_{2}+C_{p s}\right)\left(G_{p 1} G_{s}+G_{p 3} G_{p 1}+g_{m 1} G_{s}\right) \\
& -G_{p 2}\left(C_{1}+C_{2}\right)\left(G_{s}+G_{p 3}\right)-G_{p 1} G_{p 2}\left(C_{p 3}+C_{s}\right) \\
& b_{0}=g_{m 1} g_{m 2} G_{s}+g_{m 1}\left(G_{p 2} G_{s}-G_{p 1} G_{p 2}\left(G_{p 3}+G_{s}\right) .\right.
\end{aligned}
$$

Transfer functions including parasitic properties are now

$$
K_{L P}^{*}(s)=\frac{I_{L P}}{I_{I N}}=\frac{s g_{m 1} g_{m 2} C_{s}+g_{m 1} g_{m 2} G_{s}}{D^{\prime}(s)},
$$

$$
\begin{array}{r}
K_{i B P}^{*}(s)=\frac{I_{i B P}}{I_{I N}}=\frac{1}{D^{\prime}(s)}\left\{g _ { m 1 } \left(s^{2} C_{s}\left(C_{2}+C_{p 2}\right)\right.\right. \\
\left.\left.+s\left(C_{2} G_{s}+C_{p 2} G_{s}+C_{s} G_{p 2}\right)+G_{p 2} G_{s}\right)\right\}, \\
K_{H P}^{*}(s)=\frac{I_{H P}}{I_{I N}}=\frac{a_{3} s^{3}+a_{2} s^{2}+a_{1} s+a_{0}}{D^{\prime}(s)},
\end{array}
$$

and coefficients of numerator in (26) are

$$
a_{3}=C_{s}\left(C_{1}+C_{p 1}\right)\left(C_{2}+C_{p 2}\right)
$$

$$
\begin{gathered}
a_{2}=G_{s}\left(C_{1} C_{2}+C_{p 1} C_{2}+C_{1} C_{p 2}+C_{p 1} C_{p 2}\right)+ \\
C_{s}\left(C_{p 2} G_{p 1}+C_{2} G_{p 1}+C_{1} G_{p 2}+C_{p 1} G_{p 2}\right), \\
a_{1}=G_{s}\left(C_{2} G_{p 1}+C_{1} G_{p 2}+C_{p 2} G_{p 1}+C_{p 1} G_{p 2}\right) \\
+C_{s} G_{p 1} G_{p 2}, \\
a_{0}=G_{p 1} G_{p 2} G_{s} .
\end{gathered}
$$

Form of the transfer function is the same for the bandreject response $(\mathrm{BR})$, but coefficients are different, as shown.

$$
\begin{gathered}
K_{B R}^{*}(s)=\frac{I_{B R}}{I_{I N}}=\frac{a_{3} s^{3}+a_{2} s^{2}+a_{1} s+a_{0}}{D^{\prime}(s)}, \\
a_{3}=C_{s}\left(C_{1} C_{p 2}+C_{1} C_{2}+C_{2} C_{p 1}+C_{p 1} C_{p 2},\right. \\
a_{2}=C_{s}\left(C_{1} G_{p 2}+C_{p 1} G_{p 2}+C_{2} G_{p 1}+C_{p 2} G_{p 1}\right)+ \\
G_{s}\left(C_{2} C_{p 1} C_{p 2}+C_{1} C_{p 2} C_{1} C_{2}\right) .
\end{gathered}
$$

$a_{1}=C_{s}\left(G_{m 1} g_{m 2}+G_{p 1} G_{p 2}\right)+G_{s}\left(C_{p 1} G_{p 2}+C_{1} G_{p 2}+\right.$

$$
\left.C_{2} G_{p 1}+C_{p 2} G_{p 1}\right) \text {, }
$$



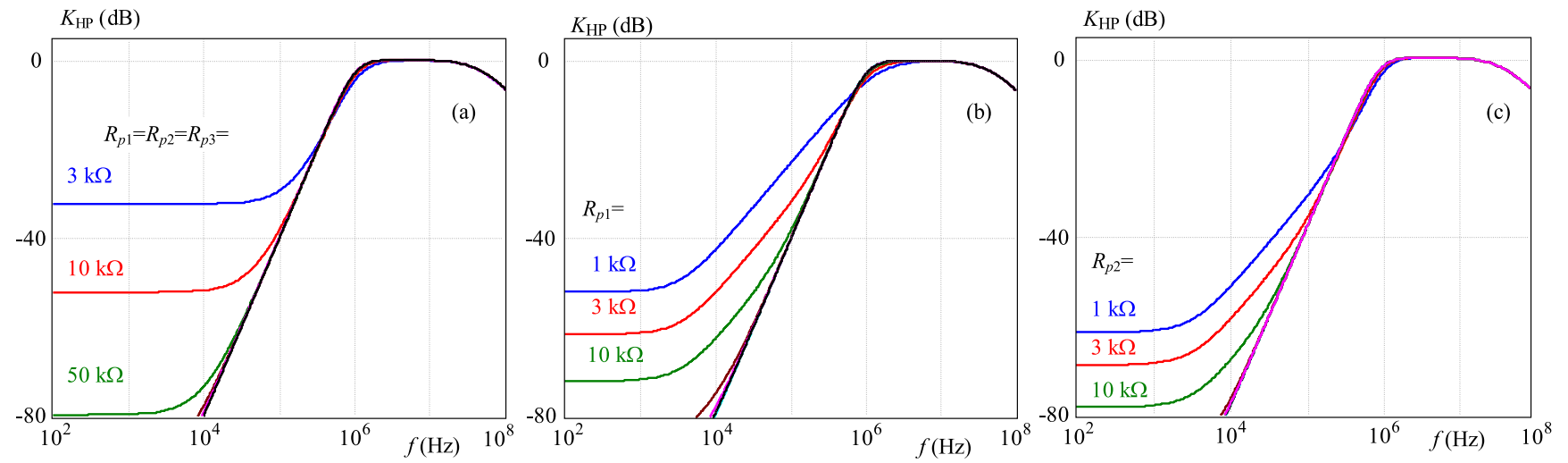

Fig. 5. Influence of $R_{p}$ parasitic elements on HP response: (a) - for equal $R_{p 1}=R_{p 2}=R_{p 3}$ values, (b)- for different $R_{p 1}$ and $R_{p 2}=100 \mathrm{k} \Omega, R_{p 3}=3 \mathrm{k} \Omega,(\mathrm{c})-$ for different of $R_{p 2}$ values and $R_{p 2}=200 \mathrm{k} \Omega, R_{p 3}=3 \mathrm{k} \Omega$
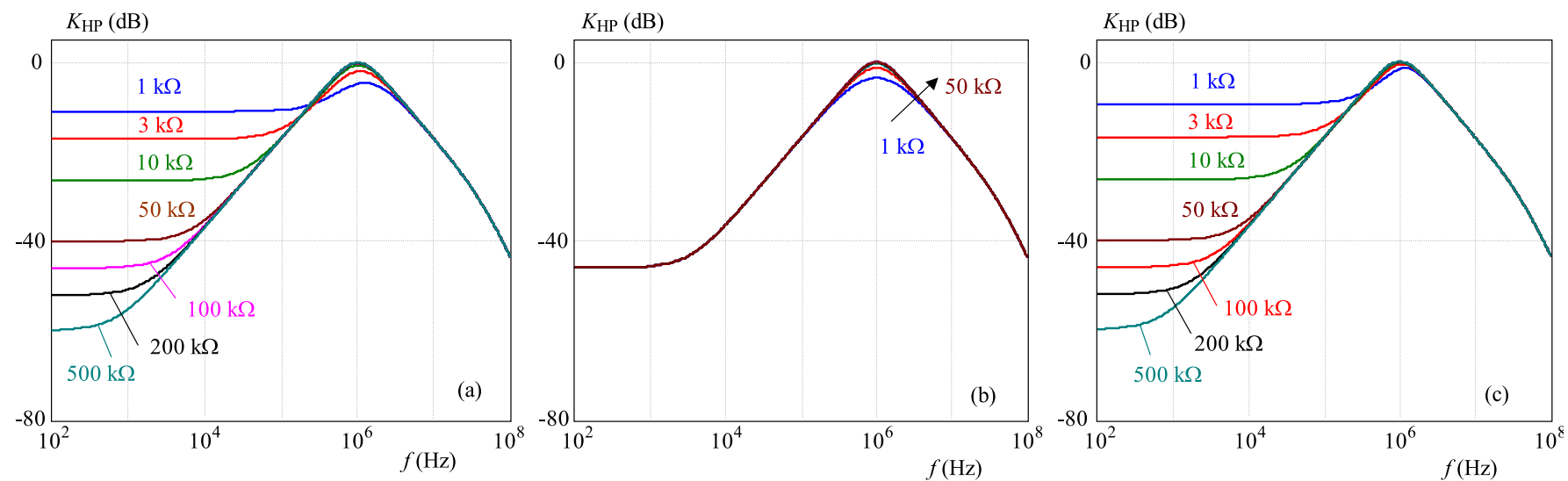

Fig. 6. Influence on $\mathrm{BP}$ response: (a) - for equal $R_{p 1}=R_{p 2}=R_{p 3}$ values, (b) - for different $R_{p 1}$ and $R_{p 2}=100 \mathrm{k} \Omega, R_{p 3}=3 \mathrm{k} \Omega$, (c) - for different of $R_{p 2}$ values and $R_{p 2}=200 \mathrm{k} \Omega, R_{p 3}=3 \mathrm{k} \Omega$

$$
a_{0}=G_{s}\left(g_{m 1} g_{m 2} G_{p 1} G_{p 2} .\right.
$$

We can express transfer function similarly for the all-pass (AP) filter

$$
\begin{gathered}
G_{A P}^{*}=\frac{I_{A P}}{I_{I N}}=\frac{a_{3} s^{3}+a_{2} s^{2}-a_{1} s+a_{0}}{D^{\prime}(s)}, \\
a_{3}=C_{s}\left(C_{p 1} C_{p 2}+C_{2} C_{p 1}+C_{1} C_{2}+C_{1} C_{p 2}\right),
\end{gathered}
$$

$$
\begin{aligned}
a_{2}=G_{s}\left(C_{p 2} G_{p 1}+C_{1} G_{p 2}+C_{2} G_{p 1}\right. & +C_{p 1} G_{p 2} \\
& \left.-g_{m 1}\left(C_{2}+C_{p 2}\right)\right),
\end{aligned}
$$

$$
\begin{gathered}
a_{1}=g_{m 1}\left(C_{2} G_{s}+C_{p 2} G_{s}+C_{s} G_{p 2}\right)-G_{s}\left(C_{p 2} G_{p 1}+C_{2} G_{p 1}+\right. \\
\left.C_{p 1} G_{p 2}+C_{1} G_{p 2}\right)-C_{s}\left(g_{m 1} g_{m 2}+G_{p 1} G_{p 2}\right), \\
a_{0}=G_{s}\left(g_{m 1} g_{m 2}+G_{p 1} G_{p 2}-g_{m 1} G_{p 2}\right) .
\end{gathered}
$$

Influence of parasitic elements on the frequency responses was deeply studied. Real part of the parasitic admittances obviously impacts mainly the magnitude response. We can divide the impact study of real parts into the two sections. First part is focused on the high impedance nodes and parasitic elements that are grounded $\left(R_{p 1}, R_{p 2}, R_{p 3}\right)$ and second part deals with serial resistance to the current input of DO-CF $\left(R_{s}\right)$.

HP responses for chosen values of $R_{p}$ parts are shown in Fig. 5a (all $R_{p}$ are of the same value in this case). It is evident that smaller values cause increase of parasitic zero frequencies and it decreases the attenuation of the HP response in the stop band. Attenuation is smaller than $40 \mathrm{~dB}$ for $R_{p}$ about units of $\mathrm{k} \Omega$. In order to study impact of $R_{p 1}$ and $R_{p 2}$, graphs in Figs. 5b and 5c were depicted. It is clear that also the change of steepness occurs (other two parameters are set constantly). It is obvious that the impact of $R_{p 1}$ is greater than impact of $R_{p 2}$. Influence of $R_{p 3}$ is negligible because this node is connected to the low input impedance of input terminal of current follower. Therefore impact is $R_{p 3}$ omitted. However, $R_{s}$ (input serial resistance of CF) also causes problems, which are discussed in further text.

Impact of $R_{p}$ on the BP response is shown in Fig. 6a and it is clear that it causes much greater problem than in the previous case (HP). Filter is unusable when values of $R_{P}$ are several units of $\mathrm{k} \Omega$. Independent change of $R_{p 1}$ (Fig. 6b) causes slight influence to the pass-band gain. Impact of $R_{p 2}$ to the stop-band attenuation of the BP response (lower frequencies) is obvious from Fig. 6c. 

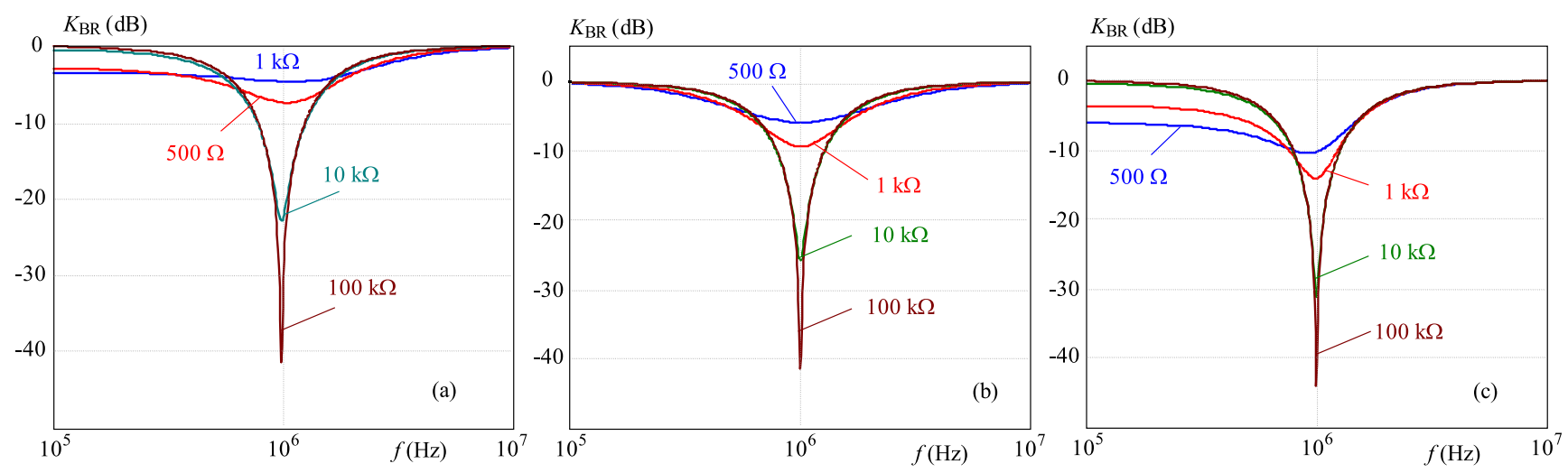

Fig. 7. Influences on BR response: (a) - for equal $R_{p 1}=R_{p 2}=R_{p 3}$ values and $R_{s}=2 \Omega$, (b) - for different $R_{p 1}$ and $R_{s}=2 \Omega$ and $R_{p 2}=100 \mathrm{k} \Omega, R_{p 3}=3 \mathrm{k} \Omega$, (c) - for different $R_{p 2}$ and $R_{s}=2 \Omega$ and $R_{p 2}=200 \mathrm{k} \Omega, R_{p 3}=3 \mathrm{k} \Omega$
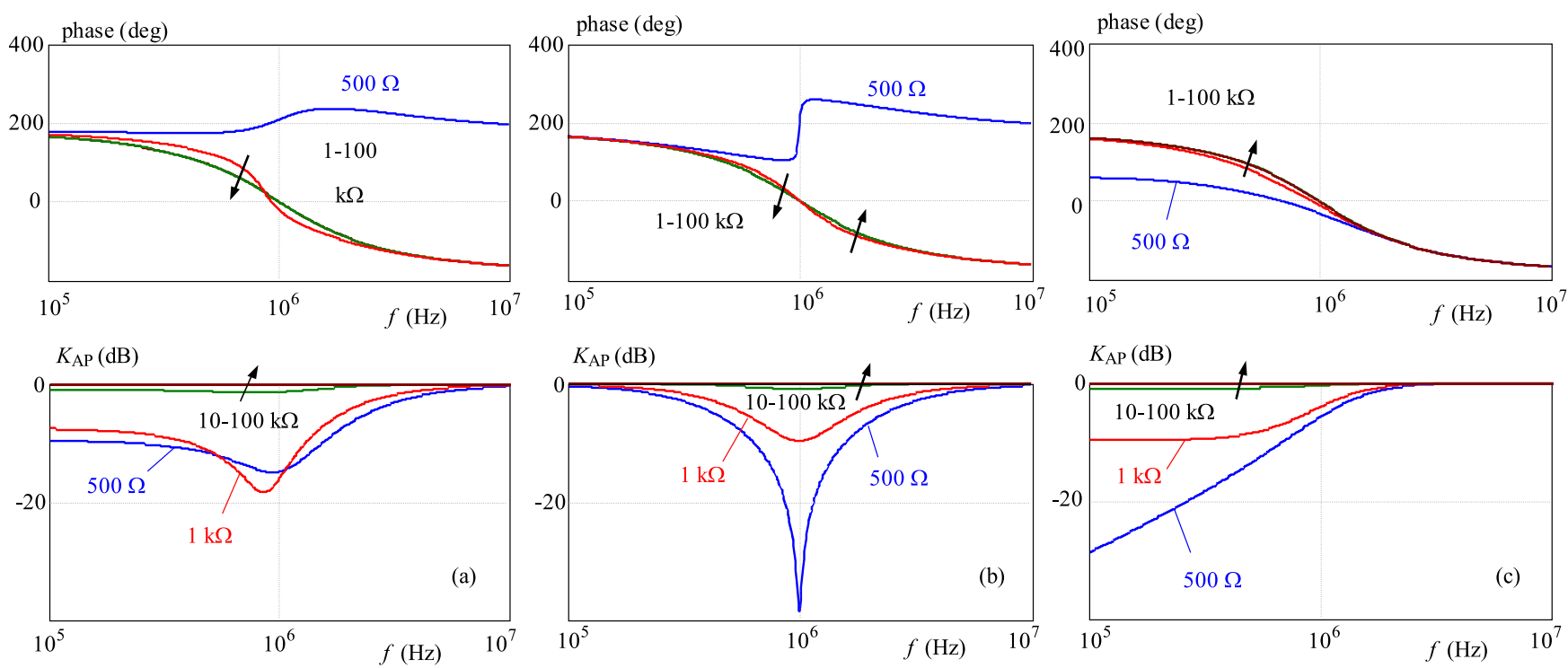

Fig. 8. Influences on AP response: (a) - of equal $R_{p 1}=R_{p 2}=R_{p 3}$ values and $R_{s}=2 \Omega$, (b) - for different $R_{p 1}$ and $R_{s}=2 \Omega$ and $R_{p 2}=100 \mathrm{k} \Omega, R_{p 3}=3 \mathrm{k} \Omega,(\mathrm{c})-$ for different $R_{p 2}$ and $R_{s}=2 \Omega$ and $R_{p 2}=200 \mathrm{k} \Omega, R_{p 3}=3 \mathrm{k} \Omega$
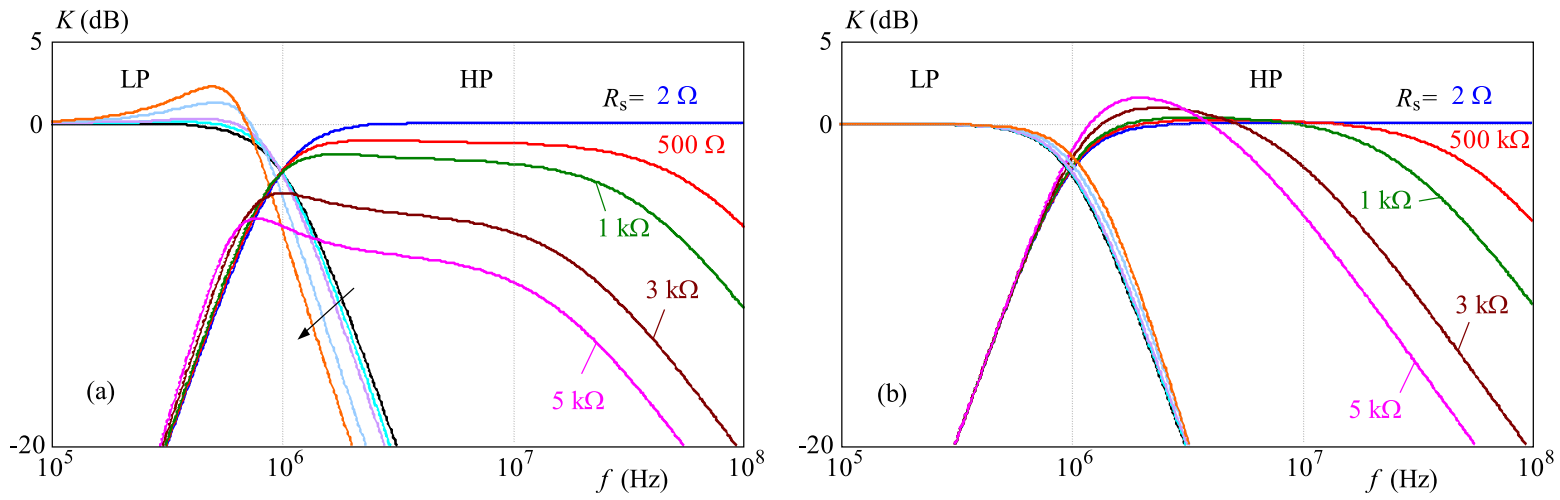

Fig. 9. Influence of different $R_{s}$ values on the magnitude of responses of the LP and HP with $R_{p 1}=200 \mathrm{k} \Omega, R_{p 1}=100 \mathrm{k} \Omega$ and: (a) $-R_{p 3}=3 \mathrm{k} \Omega$, (b) $-R_{p 3} \rightarrow \infty$

Figure 7 shows influence of $R_{p}$ on the $\mathrm{BR}$ response. We can see (Fig. 7) that $R_{p 2}$ smaller than $10 \mathrm{k} \Omega$ causes biggest problems again. $R_{p 1}$ causes the adjusting of the maximal attenuation in stop band.
Impact on the AP response is demonstrated in Fig. 8. $R_{p}$ (mainly $R_{p 2}$ ) causes drop of the transfer in the pass band (Fig. 8c) and also some changes in phase response, as shown. Figure 8b shows that $R_{p 1}$ caused changes of the 

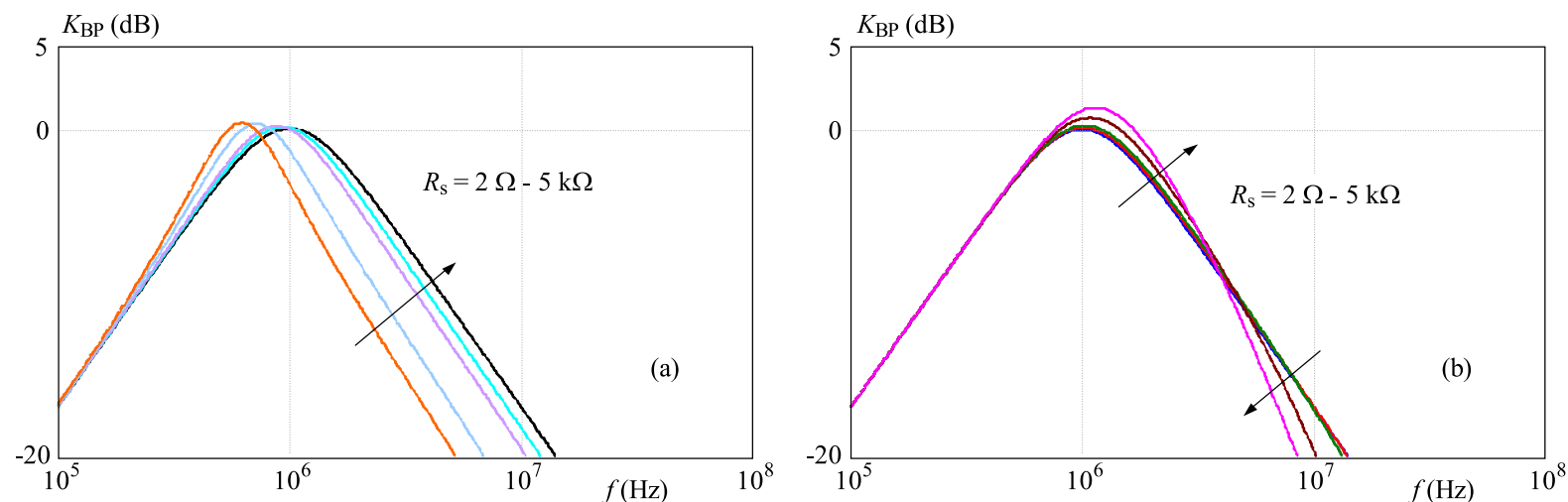

Fig. 10. Influence of different $R_{s}$ values on the magnitude of responses of the $\mathrm{BP}$ with $R_{p 1}=200 \mathrm{k} \Omega, R_{p 1}=100 \mathrm{k} \Omega$ and:

(a) $-R_{p 3}=3 \mathrm{k} \Omega$, (b) $-R_{p 3} \rightarrow \infty$
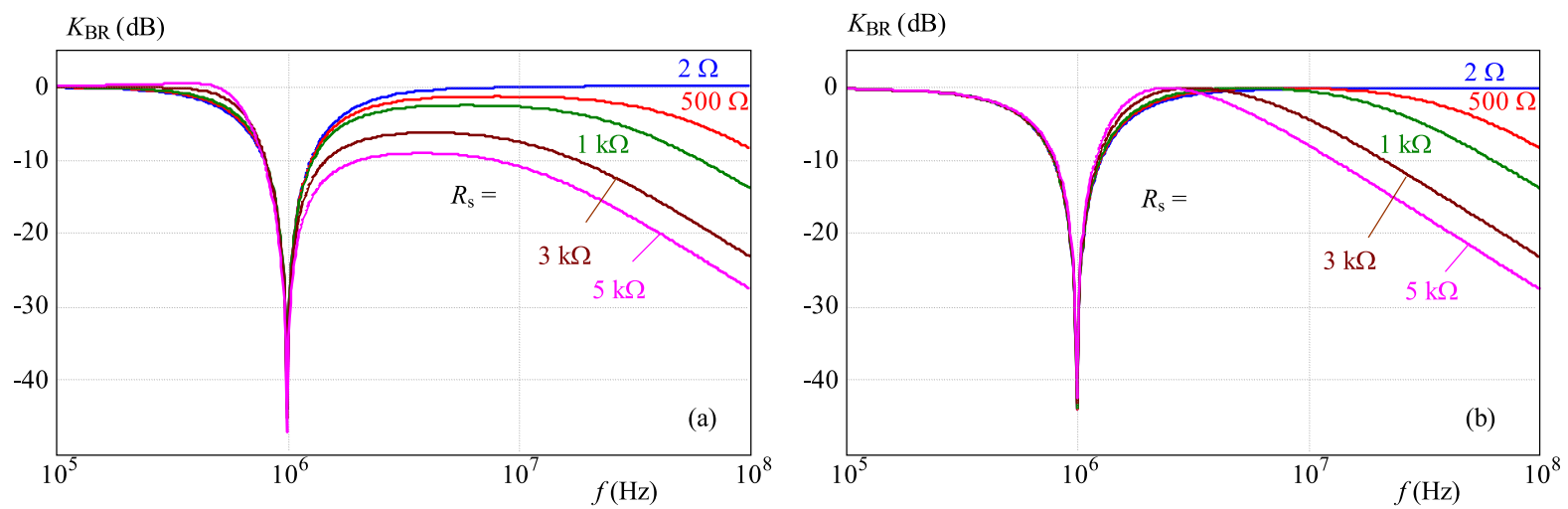

Fig. 11. Influence of different $R_{s}$ values on the magnitude of responses of the $\mathrm{BR}$ with $R_{p 1}=200 \mathrm{k} \Omega, R_{p 1}=100 \mathrm{k} \Omega$ and: (a) $-R_{p 3}=3 \mathrm{k} \Omega,(\mathrm{b})-R_{p 3} \rightarrow \infty$
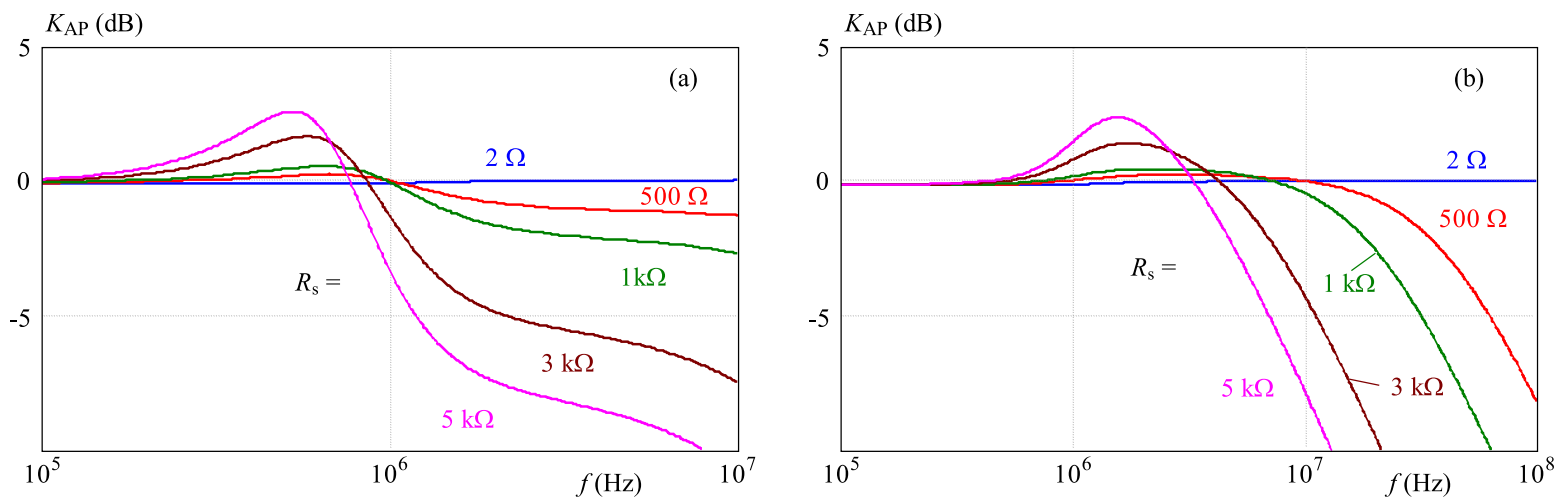

Fig. 12. Influence of different $R_{s}$ values on the magnitude of responses of the AP with $R_{p 1}=200 \mathrm{k} \Omega, R_{p 1}=100 \mathrm{k} \Omega$ and: (a) $-R_{p 3}=3 \mathrm{k} \Omega$, (b) $-R_{p 3} \rightarrow \infty$

transfer function type from the AP to the BR response and also adjusting of maximal attenuation in stop band. Threshold between AP and BR phase response is close to $R_{p 1}=500 \Omega$. In some cases it could be an advantage.

Parasitic resistance of current input of the DO-CF $\left(R_{s}\right)$ has also significant impact on the final features of the filter. Parasitic element $R_{s}$ is put to the feedback node together with $R_{p 3}$. First case (Fig. 9a) suppose that $R_{p 3}=3 \mathrm{k} \Omega$, second case (Fig. $9 \mathrm{~b}$ ) that $R_{p 3} \rightarrow \infty$. Both figures shows the impact on the LP and HP response. Reducing of the bandwidth (at high frequencies) is observed in case of HP. Disturbing of the $Q$ and pass-band gain $K_{0}$ is obvious for greater values of $R_{s}$. If $R_{p 3}$ was set to infinity (Fig. 9b) (practically is sufficient more than $100 \mathrm{k} \Omega$ ), influence on LP is minimal.

Parasitic element $R_{s}$ affects the BP response as shows Fig. 10. $R_{s}$ causes mainly shift of the $f_{0}$ and slight changes of $Q$ for $R_{p 3}=3 \mathrm{k} \Omega$ (Fig. 10a), there is slight disturbance of maximal transfer and angular frequency $\left(f_{0}\right)$ for $R_{p 3} \rightarrow \infty$ (Fig. 10b).

Also $\mathrm{BR}$ response is affected by $R_{s}$. When $R_{p 3} \rightarrow$ $\infty$ (Fig. 11b) reducing of the bandwidth is larger than 


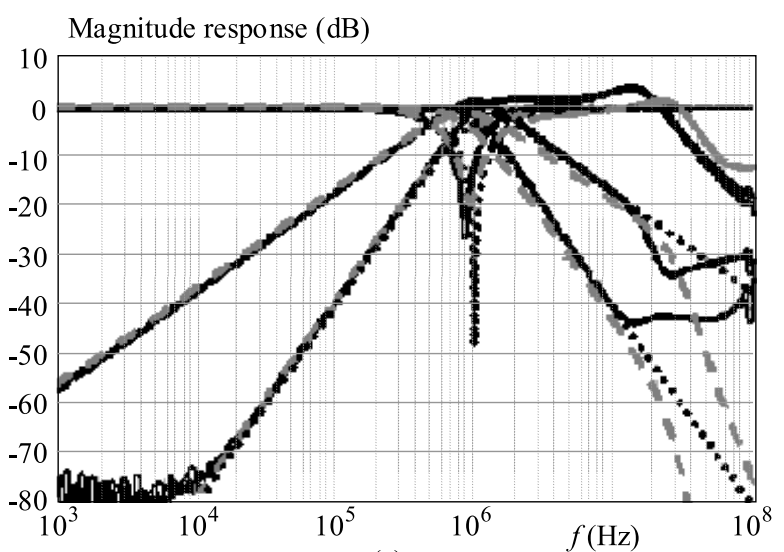

(a)

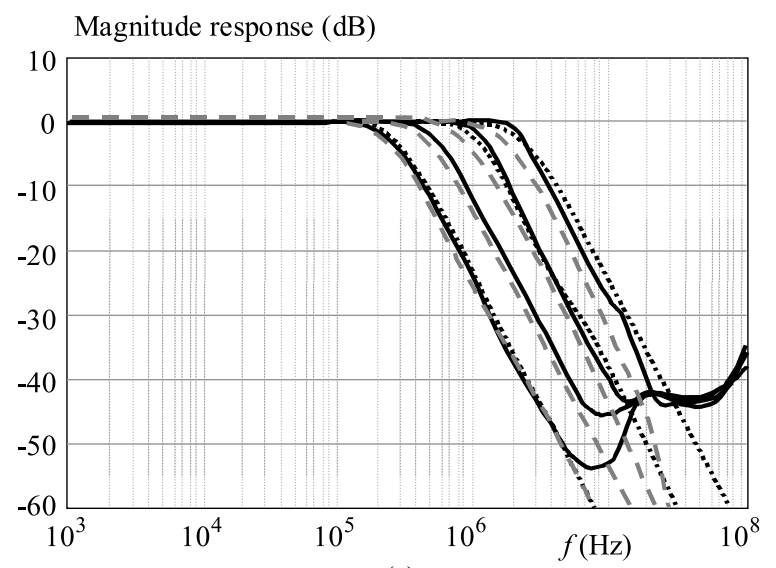

(c)

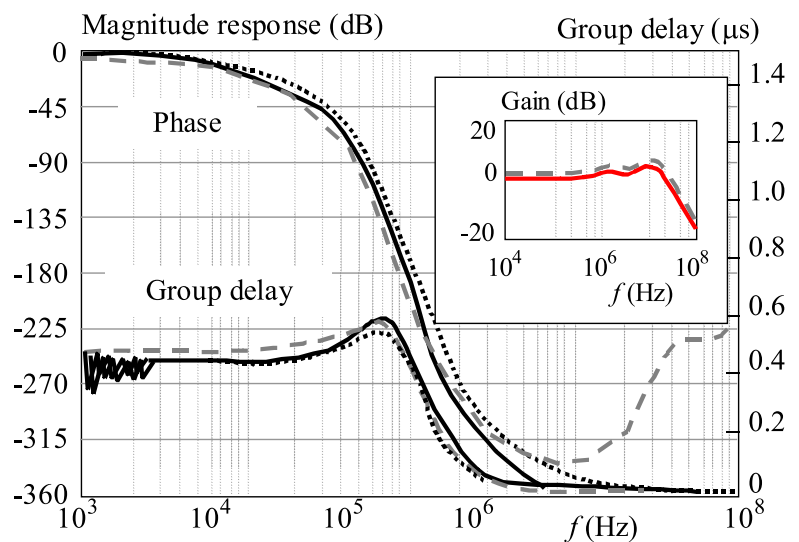

(b)

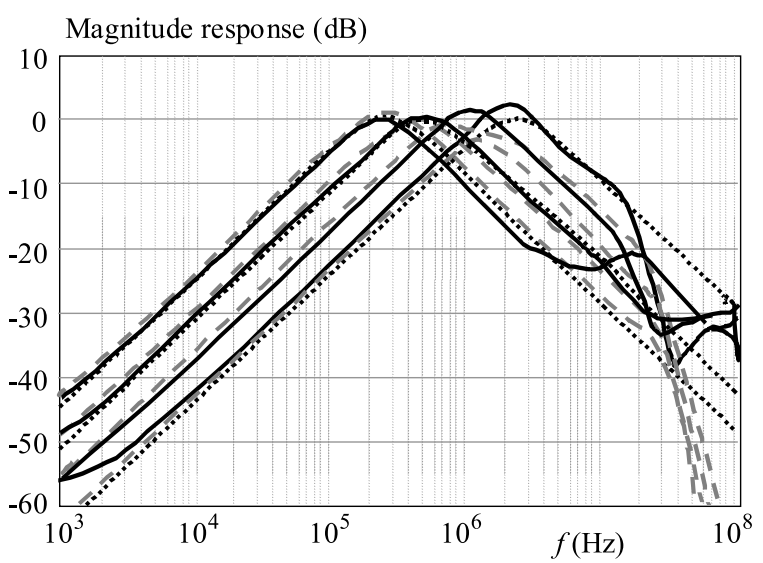

(d)

Fig. 13. a) Magnitude responses of the LP, HP, iBP and BS filters for the natural frequency $1 \mathrm{MHz}$ b) Gain, phase shift and group delay of AP filter for the natural frequency $1 \mathrm{MHz}$; Tuning of the pole frequency $\left(f_{1}=255 \mathrm{kHz} ; f_{2}=510 \mathrm{kHz} ; f_{3}=1 \mathrm{MHz} ; f_{4}=2.3 \mathrm{MHz}\right)$ in case of c) the LP filter and d) the iBP filter (dotted lines - theory; dashed lines - simulation; solid lines - measurement)

when $R_{p 3}=3 \mathrm{k} \Omega$ (Fig. 11a) but gain in pass-band is not affected so much as is obvious from Fig. 11b.

Impact of $R_{s}$ on the AP response is demonstrated in Fig. 12. Magnitude response is influenced the most in this case. It affects bandwidth, $Q$ and pass-band gain at higher frequencies. Phase response is without important changes but at higher frequencies is phase shift greater than in ideal case (non-minimal phase).

All analyses were carried out for parasitic capacitances of units of $\mathrm{pF}$ (taken from features of used active elements). Parasitic capacitances causes mainly shift of $f_{0}$. For several pF ( $30 \mathrm{pF}$ maximum) shift of $f_{0}$ from $1 \mathrm{MHz}$ to $960 \mathrm{kHz}$ appeared (caused by $C_{p 2}$ ) and shift of $60 \mathrm{kHz}$ is caused by $C_{p 1} ; C_{p 3}$ is without affect on $f_{0}$ because is in node with small impedance $\left(R_{s}=2 \Omega\right)$. Influence of all $C_{p}$ simultaneously is reaches $90 \mathrm{kHz}$ shift of $f_{0}$ (in all cases we expected ideal load $R_{L}=0 \Omega$ ). For real scenarios we have take into account that small signal parameters are also frequency-dependent but producer usually does not show these dependences.

\section{SIMULATION AND MEASUREMENT RESULTS}

The proposed numerical parameters of the filter were as follows. $Q=0.707$ (Butterworth approximation), transconductances are $g_{m 1}=g_{m 2}=1.96 \mathrm{mS}$ and $f_{0}=$ $1 \mathrm{MHz}$ is the starting point. The calculated values of capacitors are $C_{2}=g_{m 2} /(\omega Q) \approx 440 \mathrm{pF}, C_{1}=\left(g_{m 1} g_{m 2}\right) /$ $\left(C_{2} \omega^{2}\right) \approx 220 \mathrm{pF}$. Third-order behavioral models of the UCC-N1B were used for simulation purposes [19]. These models are quite accurate in $\mathrm{AC}$ simulations and with their help we can faithfully verify features of the filter.

The simulation results were subsequently confirmed by experimental measurement. The UCC-N1B circuit we designed in 2000 (and made by AMI Semiconductor in 2005 ) is able to operate as all types of active elements that are present in the filtering structure from Fig. 3. It was therefore used as the active element for measurement purposes.

The first graph (Fig. 13a) contains magnitude responses of the HP, BS, LP and iBP filter types for the starting natural frequency and quality factor. The gain, phase shift and also group delay of the AP filter for the same natural frequency are shown in Fig. 13b. The 
graphs in Fig. 13c and Fig. 13d represent the tuning of pole frequency in the case of the LP and iBP functions, which was obtained by a simultaneous change of $g_{m 1}$ and $g_{m 2}$. Four pole frequencies $\left(f_{1}=255 \mathrm{kHz}\right.$; $\left.f_{2}=510 \mathrm{kHz} ; f_{3}=1 \mathrm{MHz} ; f_{4}=2.3 \mathrm{MHz}\right)$ are obtained by the transconductances $500 \mu \mathrm{S} ; 1 \mathrm{mS} ; 1.96 \mathrm{mS} ; 4.5 \mathrm{mS}$.

We can form some interesting conclusions from previous text. From experimental results it is clear that UCC provides better performance than elements used in chapter focused on parasitic influence analysis. Some problems like attenuation at higher frequencies (over $10 \mathrm{MHz}$ ) in the case of the LP and iBP filter are caused by measuring circuits and finite bandwidth of used active elements. If we had to use MAX 435 as a BOTA, its connection to low input impedance of DO-CF eliminates the impact of the low output resistance $(3 \mathrm{k} \Omega), Y_{s} \gg Y_{p 3}\left(R_{s} \ll R_{p 3}\right)$. From analysis results it is clear that influence of $R_{s}$ (input resistance of CF) is very critical for this and a similar conception of multi-loop and multi-functional filters.

\section{CONCLUSION}

The universal filter with three simple active elements and two passive components was presented in this paper. It was demonstrated that the pole frequency could be tuned by a simultaneous change of the transconductance of both OTAs. The filter is of the SIMO type with a low-impedance input node and high-impedance outputs. There is no resistor in the structure, therefore it can be considered as the OTA-C type combined with dual-output current follower. Good characteristics of the designed filter were verified by the simulation with goodquality models. Its structure is sufficiently simple as some similar previously published solutions although there are some problems that are not discussed in recently published works. Detailed analysis of parasitic influences was performed. The theoretical and simulation results were confirmed by experimental measurement with the UCCN1B 0520 circuit.

\section{Acknowledgement}

Research described in the paper was supported by the Czech Ministry of Education under research program MSM 0021630513 and Czech science Foundation projects under No. 102/08/H027 and No. 102/09/1681. Research described in the paper is a part of the COST Action IC0803 RF/Microwave communication subsystems for emerging wireless technologies, financed by the Czech Ministry of Education by the grant no. OC09016. The authors are thankful to the reviewers for their constructive recommendations, which helped to improve this paper. The support of the project CZ.1.07/2.3.00/20.0007 WICOMT, financed from the operational program Education for competitiveness, is gratefully acknowledged.

\section{REFERENCES}

[1] TOUMAzou, C.-LidGeY, F. J.-HAigh, D. G. : Analogue IC Design: The Current Mode Approach, Peter Peregrinus Ltd, London, 1990.

[2] SENANI, R.-GUPTA, S. S.: New Universal Filter using only Current Followers as Active Elements, International Journal of Electronics and Communications (AEU) 60(3) (2006), 251-256, doi: 10.1016/j.aeue.2005.05.015.

[3] GUPTA, S. S.-SENANI, R.: New Voltage-Mode/CurrentMode Universal Biquad Filter using Unity Gain Cells, International Journal of Electronics (UK) 93(11) (2006), 769-775, doi: 10.1080/00207210600711622.

[4] JERABEK, J.-VRBA, K. : Novel Universal Filter Using Only Two Current Active Elements, Proc. Third Int Conf on Systems (ICONS08), IEEE Computer Society, 2008, pp. 285-289, doi: 10.1109/ICONS.2008.30.

[5] TANGSRIRAT, W.-PRASERTSOM, D. : Electronically Tunable Low-Component-Count Current-Mode Biquadratic Filter Using Dual-Output Current Followers, Electrical Engineering 90(1) (2006), 33-37, doi: 10.1007/s00202-006-0051-1.

[6] ABuelma'AtTi, M. T.-BENTRCiA, A.: A Novel MixedMode OTA-C Universal Filter, International Journal of Electronics 92(7) (2005), 375-383, doi: $10.1080 / 08827510412331295009$.

[7] TSUKUTANI, T.-SUMI, Y.-FUKUI, Y.: Electronically Tunable Current-Mode OTA-C Biquad Using Two-Integrator Loop Structure, Frequenz 60(3-4) (2006), 53-56.

[8] TANGSRIRAT, W.: Current-Tunable Current-Mode Multifunction Filter Based on Dual-Output Current-Controlled Conveyors, International Journal of Electronics and Communications (AEU) 61(8) (2007), 528-533, doi:10.1016/j.aeue.2006.09.005.

[9] HERENCSAR, N.-VRBA, K. : Current Conveyors-Based Circuits Using Novel Transformation Method, IEICE Electronics Express 4(21) (2007), 650-656, doi: 10.1587/elex.4.650.

[10] SIRIPRUCHYANUN, M.-JAIKLA, W. : CMOS Current-Controlled Current Differencing Transconductance Amplifier and Applications to Analog Signal Processing, International Journal of Electronics and Communications (AEU) 62(4) (2008), 277-287, doi: 10.1016/j.aeue.2007.05.001.

[11] SIRIPRUCHYANUN, M.-JAIKLA, W.: Realization of Current Controlled Current Differencing Transconductance Amplifier (CCCDTA) and its Applications, ECTI Transaction on Electrical Engineering, Electronics, and Communication 5(1) (2007), $41-50$.

[12] SHAH, N. A.-QUADRI, M.-IQBAL, S. Z.: CDTA Based Universal Transadmittance Filter, Analog Integrated Circuits and Signal Processing 52(1-2) (2007), 65-69, doi: 10.1007/s10470-007-9091-3.

[13] HERENCSAR, N.-KOTON, J.-VRBA, K.-MISUREC, J. : A Novel Current-Mode SIMO Type Universal Filter Using CFTAs, Contemporary Engineering Sciences 2(2) (2009), 59-66.

[14] JERABEK, J.-VRBA, K. : SIMO Type Low-Input and HighOutput Impedance Current-Mode Universal Filter Employing Three Universal Current Conveyors, International Journal of Electronics and Communications (AEU) 64(6) (2010), 588-593, doi: 10.1016/j.aeue.2009.03.002.

15] MINAEI, S.-YUCE, E.-CICEKOGLU, O.: ICCII-Based Voltage-Mode Filter with Single Input and Six Outputs Employing Grounded Capacitors, Circuits, Systems and Signal Processing 25(4) (2006), 559-566, doi:10.1007/s00034-005-0923-z.

[16] HORNG, J.-HOU, C.-CHANG, C.-CHOU, H.-LIN, C.: High Input Impedance Voltage-Mode Universal Biquadratic Filter with One Input and Five Outputs Using Current Conveyors, Circuits, Systems and Signal Processing 25(6) (2006), 767-777, doi: 10.1007/s00034-005-1227-z.

[17] SOliman, A. M. : Current-Mode Universal Filters Using Current Conveyors: Clasification and Review, Circuits, Systems and 
Signal Processing 27(3) (2008), 405-427,

doi: 10.1007/s00034-008-9034-y..

[18] HORNG, J.: High Input Impedance Voltage-Mode Universal Biquadratic Filter with Three Inputs Using DDCCs, Circuits, Systems and Signal Processing 27(4) (2008), 553-562, doi: 10.1007/s00034-008-9044-9.

[19] WANG, C.-LIU, H.-ZHAO, Y.: A New Current-Mode Current-Controlled Universal Filter Based on $\operatorname{CCCII}( \pm)$, Circuits, Systems and Signal Processing 27(5) (2008), 673-682, doi: 10.1007/s00034-008-9050-y.

[20] SIRIPRUCHYANUN, M.-JAIKLA, W.: Cascadable Current-Mode Biquad Filter and Quadrature Oscillator Using DO-CCCIIs and OTA, Circuits, Systems and Signal Processing 28(1) (2009), 99-110, doi: 10.1007/s00034-008-9072-5.

[21] HORNG, J.-HOU, C.-CHANG, C.-CHIU, W.-LIU, C. : Current-Mode Universal Biquadratic Filter with Five Inputs and Two Outputs Using Two Multi-Output CCIIs, Circuits, Systems and Signal Processing 28(5) (2009), 781-792, doi: 10.1007/s00034-009-9121-8.

[22] MINAEI, S.-YUCE, E. : All-Grounded Passive Elements Voltage-Mode DVCC-Based Universal Filters, Circuits, Systems and Signal Processing 29(2) (2010), 295-309, doi: 10.1007/s00034-009-9136-1.

[23] MINAEI, S.-YUCE, E. : Novel Voltage-Mode All-Pass Filter Based on Using DVCCs, Circuits, Systems and Signal Processing 29(3) (2010)), 391-402, doi: 10.1007/s00034-010-9150-3..

[24] KOKSAL, M.-SAGBAS, M. : Second Order Band-Pass Filter Design Using Single CC-CDBA, Circuits, Systems and Signal Processing 27(4) (2008), 461-474, doi: 10.1007/s00034-008-9038-7.

[25] SIRIPRUCHYANUN, M.-JAIKLA, W.: Electronically Controllable Current-Mode Universal Biquad Filter Using Single DO-CCCDTA, Circuits, Systems and Signal Processing 27(1) (2008), 113-122, doi: 10.1007/s00034-008-9014-2.

[26] KAMAT, D.-MOHAN, P. V.-PRABHU, K. : Novel FirstOrder and Second-Order Current-Mode Filters Using Multiple-Output Operational Transconductance Amplifiers, Circuits,
Systems and Signal Processing 29(3) (2010), 553-576, doi: 10.1007/s00034-010-9163-y.

[27] SOTNER, R.-PETRZELA, J.-SLEZAK, J.: Current-Controlled Current-Mode Universal Biquad Employing Multi-Output Transconductors, Radioengineering 18(3) (2009), 285-294.

[28] LEE, C. : Multiple-Mode OTA-C Universal Biquad Filters, Circuits, Systems and Signal Processing 29(2) (2010), 263-274, doi: 10.1007/s00034-009-9145-0.

Received 18 January 2011

Jan JEŘÁBEK was born in Bruntal, Czech Republic, in 1982. He received the PhD degree in Electrical Engineering in 2011 from the Technical University of Brno, Czech Republic. He received MSc and BSc degree from the same university in 2007 and in 2005 respectively. His research interests are focused on circuit applications of modern active elements such as current operational amplifiers and multiple output current followers.

Roman ŠOTNER was born in Znojmo, Czech Republic, in 1983. He received the MSc. degree (2008) from the Brno University of Technology. Currently he is a $\mathrm{PhD}$ student at the Faculty of Electrical Engineering and Communication. His interests are analogue circuits (active filters, oscillators, audio, etc.), circuits in the current mode and computer simulation.

Kamil VRBA received the PhD degree in Electrical Engineering in 1976, and the Prof degree in 1997, both from the Technical University of Brno. Since 1990 he has been Head of the Department of Telecommunications of the Faculty of Electrical Engineering and Computer Science of Brno University of Technology. His research work is concentrated on problems concerned with the accuracy of analog circuits and mutual conversion of analog and digital signals.

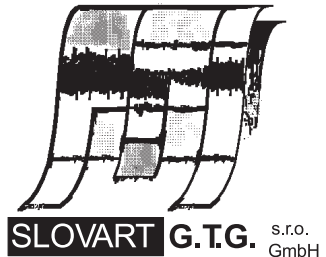

EXPORT - IMPORT
EXPORT - I M P OR T

of periodicals and of non-periodically printed matters, books and CD-ROMs

Krupinská 4 PO BOX 152, 85299 Bratislava 5, Slovakia tel: ++421 263839 472-3, fax: ++421263839485 info@slovart-gtg.sk; http://www.slovart-gtg.sk

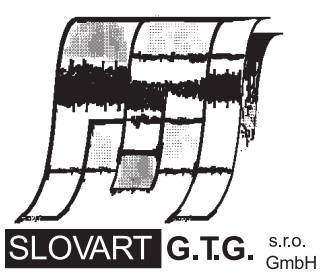

EXPORT - IMPORT 